\title{
Rhetorical Flaws in Brutus' Forum Speech in Julius Caesar: A Carefully Controlled Weakness?
}

\author{
Dominic Cheetham (Corresponding author) \\ English Literature, Sophia University, Chiyoda-Ku, Kioi-Cho 7-1, Tokyo, Japan \\ E-mail: c-domini@sophia.ac.jp
}

Doi:10.7575/aiac.alls.v.8n.3p.126

URL: http://dx.doi.org/10.7575/aiac.alls.v.8n.3p.126
Received: 27/04/2017

Accepted: 20/06/2017

\begin{abstract}
In Julius Caesar Shakespeare reproduces one of the pivotal moments in European history. Brutus and Mark Antony, through the medium of their forum speeches, compete for the support of the people of Rome. In the play, as in history, Mark Antony wins this contest of language. Critics are generally agreed that Antony has the better speech, but also that Brutus' speech is still exceptionally good. Traditionally the question of how Antony's speech is superior is argued by examining differences between the two speeches, however, this approach has not resulted in any critical consensus. This paper takes the opening lines of the speeches as the only point of direct convergence between the content and the rhetorical forms used by Brutus and Antony and argues that Brutus' opening tricolon is structurally inferior to Marc Antony's. Analysis of the following rhetorical schemes in Brutus' speech reveals further structural weaknesses. Shakespeare gives Brutus a speech rich in perceptually salient rhetorical schemes but introduces small, less salient, structural weaknesses into those schemes. The tightly structured linguistic patterns which make up the majority of Brutus' speech give an impression of great rhetorical skill. This skilful impression obscures the minor faults or weaknesses that quietly and subtly reduce the overall power of the speech. By identifying the weaknesses in Brutus' forms we add an extra element to the discussion of these speeches and at the same time display how subtly and effectively Shakespeare uses rhetorical forms to control audience response and appreciation.
\end{abstract}

Keywords: rhetoric, Julius Caesar, rule of three, tricolon, forum speech, Brutus, Antony, Shakespeare

\section{Introduction}

When William Shakespeare wrote the forum speeches for Julius Caesar he was faced with a serious problem. To be credible, Antony's speech had to be better in some way than Brutus'. Antony's speech had to overturn or negate whatever understanding or acceptance Brutus created, and it had to do so to such an extent that the people of Rome would riot and do murder for Antony's cause. It would make no sense to write a scene where the mob followed Antony if his speech were not convincingly powerful. The easy solution would be to give Brutus a weak speech that Antony could then quite easily surpass. However, this would severely damage the credibility of the play. There is no drama in following a weak speech with a stronger, but there is great drama in following a powerful piece of oratory with something still more powerful and persuasive, especially as this battle of speeches was the fulcrum upon which the whole Roman world would be moved.

The dramatic necessity for Brutus to make a good speech is argued by a number of scholars. Kolbe (1896. p. 510), and Booth (1985, p. 565) argue that the forum speeches must simultaneously convince the mob and the theatre audience. Mooney (1991, p. 44) stresses the dramatic tension stating that "the response to Brutus has been overwhelming, and they [the spectators] may well wonder whether Antony will be able to surpass him". Other writers praise Brutus' rhetorical skills, with Willson Jr. (2010) stating that, "the best skills of an academic rhetorician are here exhibited" (p. 25), and Schanzer (1955. p. 2) that "It seems to me ... an extremely shrewd and highly effective piece of oratory" (p. 2) going on to claim that "nothing could be more skilful" (p. 3), so skilful that Humphreys (2008) believes that "Shakespeare must have wondered how he could make Antony outdo it" (p. 15). Shrewd and skilful Brutus' speech may be, but Shakespeare achieved the seemingly impossible and made Mark Antony's speech even better.

The first indication of any weakness in Brutus' speech comes from the sincere but inappropriate response of the crowd. Mooney (1991) notes this, saying, "much moved by Brutus' words (though missing much of his point), the people wish to raise a statue in his honor" (p. 43). Mooney goes on to describe Antony's speech, by comparison, as "a tour de force if there ever was one" (p. 44). Hazlitt (1818) states that "Mark Antony's speech over the dead body of Cæsar has been justly admired for the mixture of pathos and artifice in it: that of Brutus certainly is not as good" (p. 40). Finally, Booth summarises the quality of the two speeches by describing Brutus' speech as "the theatrically splendid justification speech, one of the great things that a Shakespearean actor can get to do" but bemoans the impossible task of any actor who plays Brutus, because that splendid speech "is immediately succeeded by Antony's dazzling funeral speech - the best thing a Shakespearean actor can get to do" (p. 566). This paper argues that Shakespeare gives Brutus perceptually salient rhetorical schemes which give the impression of powerful, skilful oratory, but he also introduces minor, less noticeable flaws into the rhetorical schemes of Brutus' speech, thus subtly and unobtrusively weakening the speech. 


\section{Comparing the speeches}

Traditionally discussion of the forum speeches has been based in a comparative approach. Critics identify a difference such as the length of the speeches, use of irony, use or type of rhetorical figures, use of prose or verse, and then argue for the superiority of some quality or combination of qualities in Mark Antony's speech in relation to Brutus'. However, this approach, while it produces a good deal of interesting analysis, generally fails to produce any kind of consensus, and opposing interpretations are common. For example, Brutus' speech is considerably shorter than Antony's and Newman (2007, pp. 42-3) argues that because this necessarily entails a comparative lack of detail and concrete examples it is a weakness in the speech. Schanzer (1955), on the other hand, defends the lack of detail, arguing that "the speech is kept as short as possible, so that detailed accusations would seem out of place" (p. 2).

Antony also makes exceptional use of irony (Sperber \& Wilson, 1998, pp. 140-155; S'hiri 1992, pp. 124-134; Gilbert 1997, pp. 309-323), something that Brutus uses not at all, and, linked with that irony, Antony lies, deceives and manipulates (Newman, 2007, p. 47; Fuzier, 1974, p. 50), whereas Brutus is steadfastly honest. But whilst it is true that irony or deception can be effective speech making techniques, so too can be directness and honesty, and as such there are no grounds here to claim that Antony's speech is better or more effective for either irony or deception of themselves.

The two speeches are also very different in form. Both speeches use a large number of rhetorical figures. Fuzier (1974, p. 44) identifies thirty different figures used a total of over sixty times for Brutus, and fifty-two figures used by Antony a total of one hundred and three times. However, because Brutus' speech is shorter, his has a greater concentration of figures, and because he uses schemes, or figures based in linguistic form, as opposed to Antony, who mainly uses tropes, or figures based in meaning or content, Brutus' figures are more perceptually salient than Antony's. Kolbe (1896) praises Brutus for delivering "the nearest approach which our language has ever made to the sententious classic style" (p. 511). Zandvoort (1940) stresses the uniqueness of this style by stating that "Brutus' speech is the most prominent example in Shakespeare of the sustained use of rhetorical 'schemes"' (p. 66). Fuzier (1974) describes the speech as "a perfectly constructed and perfectly balanced piece of eloquence, which complies with all the requirements of the genre" (p. 27), and Schanzer (1955) praises "his clipped, carefully patterned phrases" (p. 2). Newman (2007) also praises Brutus' speech as "artfully crafted, with strong parallel statements and rhythmic repetitions" (p. 44). However, other critics are less impressed. Kraemer (1991) talks of "the thoughtnumbing uniformity of Brutus' polished figures" (p. 170), and Wills (2011) describes the styles as "contrived and artificial" (p. 41), later adding that, "Brutus' rhetoric is so overdone that it approaches what is comic elsewhere in Shakespeare" (p. 54). There is clearly no commonality of opinion. What is clear, though, if we think of the speeches of Martin Luther King Jr. or Winston Churchill, is that a rhetorically dense speech is not in any way necessarily worse than a less rhetorically dense speech. Likewise, if we think of Lincoln's Gettysburg Address, we can see that there is no necessary weakness in a very short speech.

Similar conflicts of opinion can be found in discussion of the emotional content of the speeches, or of Brutus' use of prose compared to Antony' verse. Vickers (1968) criticizes Brutus' “emotionless attitude” (p. 243), but Fuzier (1974) defends the lack of emotion as appropriate and correct for a character who is a "self-professed Stoic" (p. 46). Wilson Jr. (2010) links Brutus' use of prose to a lack of passion, arguing that "rendered in dispassionate prose, the justification exposes the speaker's blindness to the reality of human emotion" (p. 25). Both Wills (2011, p. 59) and Vickers (1968, p. 248) equate the use of prose with a prepared speech and both treat this as a weakness. Vickers states that the speech is "penned and learned in a vacuum, oblivious to the audience's response to it either during or after its delivery" (p. 243), and Wills that "Brutus reads his cold and studied text" (p. 59). Other commentators, however, view the use of prose differently. With the exception of the Forum Speech, Brutus uses verse throughout the play, thus marking this piece off as different to his normal use of language. But there is a simple explanation for this. Brutus planned a killing, and knew that if the plan was successful and Caesar was dead, then he would have to justify his actions. Like any good student of rhetoric he would obviously then prepare a speech. The speech is in prose because it is prepared in advance. Brutus speaks in prose because, according to Fuzier (1974) that is "the natural medium of oratory" (p. 27). Prose is more suited to a logical, rational speech such as Brutus gives, just as verse is well suited to the emotive speech which Antony gives, or, as Zandvoort (1940) says, “and why this kind of prose? Because it is pre-eminently a style for the intellect; Antony's appeal will be entirely to the emotions" (p. 65). Brutus' prose, therefore, is suited to his personality, his chosen style of rhetoric, and to the fact of having prepared the speech in advance, which, if competently done, should be an advantage rather than a disadvantage. There is no reason to assume that use of prose is a weakness. Neither is there any reason to assume that a prepared speech is somehow inferior to a spontaneous speech. Indeed, Fuzier singles out the words which Brutus utters in response to Antony arriving with Caesar's body as the only un-prepared part of his speech, and suggests that this short improvised piece is slightly less competent than the prepared main body of the speech, thus indicating the superiority of the prepared speech (Fuzier, 1974, p. 32, 47). As with other criticisms of Brutus' speech, there is no real justification for the claim that prose is inherently inferior to verse. What seems most likely is that the prose/verse distinction is simply one of many differences introduced by Shakespeare to set Brutus' speech apart from Antony's (Zandvoort, 1940, p. 65), and not coincidentally, to make direct comparison difficult.

To put the whole discussion into context, in the introduction to the Arden Shakespeare edition of Julius Caesar David Daniell (2008) is critical of Brutus as "indifferent to feeling" (p. 56) notes his "logical flimsiness" (p. 55) his failure in "not leaving room for explanation of the events" (p. 56) and criticizes the speech as prepared, "detached from both the moment of delivery and the effect on the audience" (p. 56). In the Oxford Shakespeare edition however, Arthur Humphreys (2008) describes Brutus' "noble economy" (p. 18) explains that "Shakespeare fits the oration admirably to Brutus' intellectual-idealist nature and to what Plutarch calls his 'gravity and constant mind"' (p. 18) and goes on to 
describe the speech as "deeply moving despite its control, moving not by extravagance but by conviction and devotion" (p. 18). That such disparate points of view can be presented in what are, after all, balanced academic introductions rather than attempts to argue original points of view, is symptomatic of the enduring lack of agreement about exactly how Brutus' speech is weaker than Antony's.

Brutus' speech and Antony's speech are different in many ways and it perfectly possible that Shakespeare deliberately made the speeches as different as possible in order to make it difficult to judge them in relation to each other. Just as we can find many differences between bananas and oranges, but it is almost impossible to judge one better than another in terms of those differences. It is only where Brutus and Antony are doing the same things in the same way that they can be usefully compared, and there is only one such point of contact between the two speeches, the opening words, where both speakers greet the crowd using the classical rhetorical scheme of the tricolon. A weakness in Brutus' use of the tricolon leads us to examine his other schemes for possible weaknesses.

\section{The opening words}

Brutus and Antony's speeches are thoroughly dissimilar. They are different in content, aim, rhetorical style, rhetorical density, length, honesty, degree of detail, use of irony, speaker/audience relationships, use of prose or verse, and no doubt many other important areas as well. In short, they are so dissimilar that, like bananas and oranges, they resist direct comparison. However, in the openings to the two speeches Antony and Brutus are both carrying out the same speech function of greeting the crowd, and they do so with essentially the same rhetorical figure, and with almost the same words. Let us put the two openings side by side:
Brutus:
Romans, countrymen and lovers (Julius Caesar, 3.2.13)
Antony:
Friends, Romans, countrymen (Julius Caesar, 3.2.74) (Note 1)

Both openings are examples of the same rhetorical figure, a three-part sequence variously called tricolon, triplet, triad, or more generally, the rule of three. For this discussion I shall use 'the rule of three' as it is the most global and inclusive of these terms. Both Antony and Brutus are using the rule of three, and if we take 'lovers', in this situation, to be a synonym of 'friends', then the meanings of the words they use are also the same. The words and the figures are almost identical, so we are left with the question of why is it that so many people in the English speaking world remember Antony's words, why so many homepages include Antony's words as examples of tricolon or rule of three, but Brutus' very similar words are more commonly ignored or forgotten. Brutus' words, unlike Antony's, fail to lodge in the mind, and fail to make any deep or lasting impression. The explanation lies in the details of the use of the rule of three.

The rule of three comes in a wide range of internal complexity. At its most simple it can be the same word repeated three times, as with Hamlet's "Words, words, words" (Hamlet, 2.2.192). With slightly more complexity it may be three different things linked by a common category, as with the animals in Lear's "why should a dog, a horse, a rat, have life" (King Lear, 5.2.280). The linking concept may be more abstract, as with King Richard's "let's talk of graves, of worms, and epitaphs" (Richard II, 3.2.145). The three parts can be made up of phrases rather than just single words, and in that case, some degree of parallelism between the phrases, or phrasal repetition, can be part of the form. However, the rule of three can also have structure, sequence and progression (Cheetham, 2002, pp. 66-71). In Maria's famous letter in Twelfth Night "Some are born great, some achieve greatness, and some have greatness thrust upon them" (2.5.156-159) we see an expanding sequence where each road to greatness is in some way more great that the one before it. Phonological progressions are also important. In each consecutive part of this example the numbers of syllables for each part are also in an expanding progression, matching the meanings of the words. As such, this example has a parallel progression of increasing length and increasing greatness, which is made perceptually salient and more powerful by the parallelism between the parts.

If we now return to the opening lines of Brutus and Antony's speeches we can see that although they share the same meanings, and are both examples of the rule of three, Antony's words have a progression of addressee, metaphorically moving outwards. Antony's address starts close and intimate with 'friends', expands to include all those who might be 'Romans', presumably the citizens of Rome, and then extends further to include the entire audience with 'countrymen'. The sequence is smooth, consistent, and follows a rule of progressive expansion and greater inclusion of the audience (we could easily extrapolate the sequence to imagine a fourth element of something like 'people of the republic'). Also, unsurprisingly, the syllable count for each word echoes that expanding progression in a 1, 2, 3 sequence. Brutus, on the other hand, starts in the middle distance with 'Romans', moves out to include the whole audience, and then moves back in to focus on 'lovers'. The sequence changes direction, has no internal structure, no predictive power, and the syllable count of 2, 3, 2 (or 2, 3, 3 if we count 'and') not only lacks structure or predictability, but fails to parallel the meanings. In short, while both men use the same basic rhetorical device, and utter almost exactly the same words with almost exactly the same meaning, Antony's progressions of both meaning and prosody are coherent, structured, and predictive, whereas Brutus' are incoherent, unstructured, and seemingly random.

It is also worth noting that if it were not for that small word 'and', Brutus' final 'lovers' could be seen as a redefinition of 'Romans' and 'countrymen' as 'lovers', his close friends, and the sequence would then be strong and meaningful, and a suitable pause or marked change in tone in the speaking of the line could make for a stronger sequence of sounds. But Shakespeare does give Brutus that 'and' which makes such a reading very improbable, and which ultimately leaves the 
sequence weak and ineffectual. Shakespeare has therefore given Brutus a powerful and effective device to use, but has given it to him in a flawed and imperfect state. Of Brutus' opening words, Fuzier (1974) states that "there could hardly be a better mode of approach in the circumstances, at least for a politician speaking by the book" (p. 28), but even so, Shakespeare manages to create a better one for Antony.

These opening words are probably the only place where Brutus and Antony make parallel utterances, but they give a facinating example of how very minor changes can influence the power of this technique. The evidence that Shakespeare has deliberately introduced weaknesses into Brutus' speech is still slight, but it is enough to encourage us to look at Brutus' other rhetorical figures to see if they too, are in any way flawed.

\section{Brutus' other figures}

Almost all of Brutus' speech is made up of the tight linguistic patterning of classical rhetorical schemes, and most of these are subsumed into tripartite groups of phrases. As such, the rule of three is the major structuring technique which is used in Brutus' speech. After the superficially powerful, but nonetheless flawed opening, Brutus' next words are:

a) hear me for my cause, / and be silent, / that you may hear.

b) Believe me for mine honour, / and have respect to mine honour, / that you may believe.

c) Censure me in your wisdom, / and awake your senses, / that you may the better judge.

(Julius Caesar, 3.2.13-17) (Note 2)

We have a sequence of three sentences, with each sentence made up of three clauses. The structure, sequencing and wording of the sentences is roughly parallel, making it a complex and sophisticated nesting of rhetorical figures. The complexity is perceptually salient and gives the impression of great rhetorical skill, especially to those, who like Shakespeare, lived through the rhetorical drills and practices of the Elizabethan school (Joseph, 1962). However, close examination, as with the opening words of the speech, reveals weaknesses in the form:

i) Each sentence, except for the last, starts and ends with the same word (epanalepsis). In sentence 'c' 'censure' and judge' 'are rough synonyms (except that 'censure' is more negative), so the repetition of meaning is mostly preserved, but the framing power and the phonological impact of the exact repetition is lost.

ii) The opening words of each sentence (hear, believe, censure) have 1, 2, and 2 syllables respectively. The final words of each sentence (hear, believe, judge) have 1,2, and 1 syllables respectively. The lack of symmetry between 'censure' and 'judge' therefore, does not only disrupt the pattern of simple lexical repetition, but also creates a less powerful progression of word length.

iii) In clause one of sentences ' $a$ ' and ' $b$ ' the possessive pronouns ('my' and 'mine') are different. Consistency would make the pattern stronger. The change of focus to 'your' in sentence ' $c$ ' is not problematic as it is consistent with common use of the rule of three, where, if any variation or change is found, it is found in the third part (Cheetham, 2002, pp. 68-9)

iv) Clause two of sentence ' $b$ ' is longer than in sentences ' $a$ ' or 'c' because 'mine honour' is repeated. Omitting 'mine honour' and simply saying 'and have respect' would preserve the patterns of grammar and sound.

v) 'Censure' in sentence 'c' has a similar sound to 'senses' in the second clause. This makes the two words more perceptually linked and salient, and further detracts from the salience and power of the final word 'judge'.

vi) The phonological similarity between 'censure' and 'senses' also detracts from the phonological link between 'silent', 'respect' and 'senses'.

This list of faults may seem overly picky, especially as none of them (except perhaps the first) are very perpetually salient. However, it is exactly because they are not very perceptually salient that introducing these weaknesses would have been a particularly effective way for Shakespeare to weaken Brutus' speech whilst at the same time giving it a very impressive surface complexity. The opening line which Shakespeare gives to Antony is sufficient evidence that he could create a perfectly structured figure if he wished, and the many other examples of well formed rhetorical forms throughout his work confirm Shakespeare's rhetorical skill. It may be a joke, but there is still good reason for Mark Forsyth (2013) to say "when it comes to tricolons, Shakespeare had been there, done that, and bought the T-shirt" (p. 86).

As a rhetorical, or speech making exercise, we could try to re-write this whole section in a more balanced form:

hear me for my cause, / and be silent, / that you may hear.

Believe me for my honour, / and have respect, / that you may believe.

Measure me in your wisdom, / and awake your senses, / that you may take the better measure. 
'Measure' is almost certainly not the perfect choice for the last sentence, but then, I am not Shakespeare, who, if Forsyth is correct, could have re-written this piece considerably more effectively, or, more to the point, could have written it considerably more effectively in the first place, and without any need for improvement.

If Shakespeare's aim is to make minor but unobtrusive errors in the rhetorical figures, then he should not introduce errors into every part of the speech, for then there would be a danger that they would become irksome and overly noticeable. In the next part Shakespeare has given Brutus a stronger piece of talk:

If there be any in this assembly, any dear friend of Caesar's, to him I say, that Brutus' love to Caesar was no less than his.

If then that friend demand why Brutus rose against Caesar, this is my answer -

Not that I loved Caesar less, but that I loved Rome more. (Julius Caesar, 3.2.17-22)

Here the only comments I might make are that, overall this may have been better with a three part structure rather than a two part structure, and that the use of the words 'to him', 'his' and 'that friend' serve to distance the words from the audience. To use 'to you', 'yours' and possibly 'you, friend' would create a more direct connection with the members of the crowd, but this is not a fault in rhetorical structure, and is different in nature to what has been discussed so far. The immediately following chiasmus, however, does have structural irregularities:

Had you rather Caesar were living and die all slaves, than that Caesar were dead, to live all free men? (Julius Caesar, 3.2.22-24)

Ideally, the crossed over parts of a chiasmus should be the same word-forms and should be in the same grammatical category, what Hoey (1991, p. 53) describes as 'simple lexical repetition'. However, 'were living' is matched here with 'live', and 'die' is matched with 'were dead'. It is a simple matter to align them;

Had you rather Caesar live, and you die all slaves, than that Caesar die, and you live all free men? (Adapted from Julius Caesar, 3.2.22-24)

The following two sections are linked, and can be examined together:

$1 \quad$ As Caesar loved me, I weep for him;

2 as he was fortunate, I rejoice at it;

3 as he was valiant, I honour him:

4 but, as he was ambitious, I slew him. (Julius Caesar, 3.2.24-27)

$5 \quad$ There is tears for his love;

6 joy for his fortune;

7 honour for his valour;

8 and death for his ambition. (Julius Caesar, 3.2.27-28)

One of the features of the rule of three is that if there is deviation from the pattern it should come later, usually in the third part, but where there is a major deviation or even a reversal, that it might come in a fourth part (the rule of three is rather inaccurately named). In these examples Shakespeare follows the rule perfectly. The major deviation from praise and positive reaction to the negative of censure and death is in the fourth and eighth positions where it has the greatest power. However, the superbly powerful fourth part is weakened by irregularities in the preceding parts. Parts 2,3 , and 4 use the form 'as he/Caesar was [adjective]', but the first part uses a different form. We cannot adapt the first part to correspond with the following three without removing Brutus [me] from the phrase, but variations such as 'as Caesar was loyal, I weep for him,' or 'as Caesar was true, I weep for him' are possible. These changes not only maintain the structure but also have a compatible syllable count.

Also in this section, only part 2 ends with 'it'. Parts 1, 3 and 4 all end with 'him'. It is not a great change to remove the discord and have instead 'as he was fortunate, I rejoice for him', though even this is not perfect as it results in a greater number of syllables than in parts 1 and 3. Ideally, parts 1, 2 and 3 should all have the same number of syllables so as to make more salient the lower number in part 4 , which, by being lower, naturally results in a slower, graver, delivery. To balance the number of syllables, something like 'as he was fortunate, I applaud him' would work better. 
For the linked section which immediately follows (5-8), there are no structural irregularities, which somewhat reduces the negative impact of the earlier section, and most importantly, reduces the perceptual salience of the earlier irregularities.

The final part that I shall examine is the set of three rhetorical questions which Brutus addresses to the crowd:

\begin{tabular}{|c|c|}
\hline la & Who is here so base that would be a bondman? \\
\hline $1 \mathrm{~h}$ & If any, speak; for him have I offended. \\
\hline $2 a$ & Who is here so rude that would not be a Roman? \\
\hline 0 & If any, speak; for him have I offended. \\
\hline & Who is here so vile that will not love his country? \\
\hline & If any, speak; for him have I offended. (Julius Caesar, 3.2.29-34) \\
\hline
\end{tabular}

Here the three-part sequence is good, progressing from the personal and practical of being a bondsman through the more idealistic of being a Roman to the still more impersonal and abstract of loving his country. The alliteration between the adjectives and their nouns is largely consistent; 'base' with 'bondsman' and 'rude' with 'Roman'. 'Vile' does not alliterate cleanly with 'love', but there is a repeating ' $v$ ' sound, and since this is part three of another example of the rule of three, some leeway is perfectly normal. The only real problem is that the second and third questions have the negative form 'who here is so [adjective] that would not (verb, object)]' but the first question has a positive form. Inconsistency in the third part is normal, but in the first part is a major weakness in the rule of three. To make a more consistent example we would need something like 'who is here so foul that would not be a free man?'

\section{Conclusion}

The two forum speeches of Julius Caesar have been the object of a great deal of comparative discussion, but very little of that discussion has been centred around the use of rhetorical techniques. Existing rhetorical studies of the speeches, such as Fuzier (1974) and Zandvoort (1940), focus on describing the rhetorical forms used rather than on examining the execution of those forms. Non-rhetorical analysis, while often powerfully argued, fails to produce a consensus on just how Brutus' speech is weaker than Antony's. In this analysis we examine the structural features of Brutus' rhetorical schemes and argue that Shakespeare has introduced flaws into the speech in order to subtly weaken the power of the words. Of course, it is possible that Shakespeare introduced these flaws for other reasons, but it seems most probable that these flaws were a subtle, but deliberate, weakening of the speech. The simple fact that the structure of the forms is quite easily improved upon is sufficient evidence that the flaws were not simply Shakespeare making mistakes or producing a piece of slightly thoughtless writing. Indeed, the figures which Shakespeare gives to Brutus are complex and sophisticated, and are impossible to create without both great skill and careful thought, and these weaknesses are incongruous for that reason alone.

\section{References}

Booth, S. (1985). The Shakespearean actor as kamikaze pilot. Shakespeare Quarterly, 36(5), 553-570. http://www.jstor.org/stable/2869769

Cheetham, D. (2002). The rule of three (or four) and pairs. English Literature and Language, 39, 63-84.

Daniell, D. (2008). Introduction. In D. Daniell (Ed.), Julius Caesar (pp. 1-147). London: The Arden Shakespeare, Bloomsbury.

Kraemer, D. J. (1991). 'Alas, thou hast misconstrued every thing': Amplifying words and things in Julius Caesar. Rhetorica: A Journal of the History of Rhetoric, 9(2), 165-178. http://www.jstor.org/stable/10.1525/rh.1991.9.2.165

Forsyth, M. (2013). The Elements of Eloquence: How to Turn the Perfect English Phrase. London: Icon Books Ltd.

Fuzier, J. (1974). Rhetoric versus rhetoric: A study of Shakespeare's Julius Caesar act III scene 2. Cahiers Elisabethains, 5, 25-65.

Gilbert, A. (1997). Techniques of persuasion in Julius Caesar and Othello. Neophilologus, 81, $309-323$. http://link.springer.com/article/10.1023/A:1004251202026

Hazlitt, W. (1818). Characters of Shakespeare's Plays. London: Taylor and Hessey.

Hoey, M. (1991) Patterns of lexis in text. Oxford: Oxford UP.

Humphreys, A. (2008). Introduction. In A. Humphreys (Ed.), Julius Caesar (pp. 1-83). Oxford: Oxford World's Classics, Oxford UP.

Joseph, S. M. (1962). Rhetoric in Shakespeare's Time: Literary Theory of Renaissance Europe (Vol. 12). San Diego: Harcourt, Brace \& World.

Kolbe, F.C. (1896). Shakespeare's Julius Caesar. II: The Brutus difficulty. The Irish Monthly, 24(280), 505-515. http://www.jstor.org/stable/20499030 
Mooney, M.E. (1991). 'Passion, I see, is catching' The rhetoric of Julius Caesar. The Journal of English and Germanic Philology, 90(1), 31-50. http://www.jstor.org/stable/27710456

Newman, S.A. (2007). Using Shakespeare to teach persuasive advocacy. Journal of Legal Education, 53(1), 36-59. http://www.jstor.org/stable/42894007

S'hiri, S. (1992). A Pragmatics of verbal irony in literary discourse: An example from drama. Edinburgh Working Papers in Linguistics 3, 124-134.

Schanzer, E. (1955). The tragedy of Shakespeare's Brutus. ELH A Journal of English Literary History, 22(1), 1-15. http://www.jstor.org/stable/2872001

Sperber, D. and Wilson, D. (1998). Rhetoric and relevance. In D. Wellbery and J. Bender (Eds.), The Ends of Rhetoric: History, Theory, Practice (pp. 140-155). Stanford: Stanford UP.

Vickers, B. (1968.) The Artistry of Shakespeare's Prose. London: Methuen.

Wills, G. (2011). Rome and Rhetoric: Shakespeare's Julius Caesar. New Haven: Yale UP.

Willson Jr, R. F. (2010). Julius Caesar: The forum scene as historic play-within. In H. Bloom (Ed.), Bloom's Modern Critical Interpretations: Julius Caesar-New Edition (pp.19-30). New York: Infobase, 2010.

Zandvoort, R.W. (1940). Brutus' forum speech in Julius Caesar. The Review of English Studies, 16(61), $62-66$. http://www.jstor.org/stable/510028

\section{Notes}

Note 1. All examples are from The Arden Shakespeare: Julius Caesar, ed David Daniell (London: Bloomsbury, 1998)

Note 2. All examples from Brutus' speech are rearranged for ease of comparison but the wording is unchanged. 